\title{
Minimizing reflux after peroral endoscopic myotomy: navigational pocket technique
}

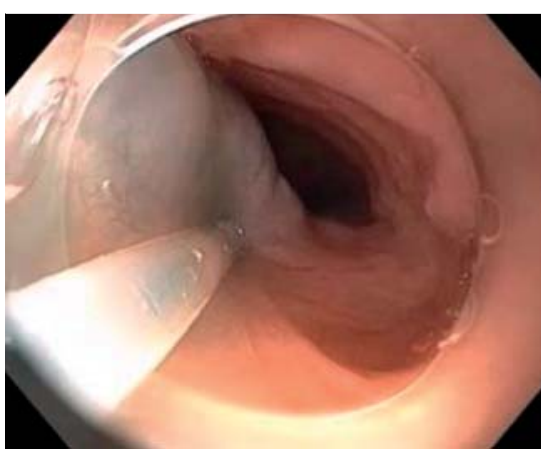

Fig. 1 Continuous mucosal elevation with the desired submucosal tunnel configuration was achieved before submucosal tunneling.

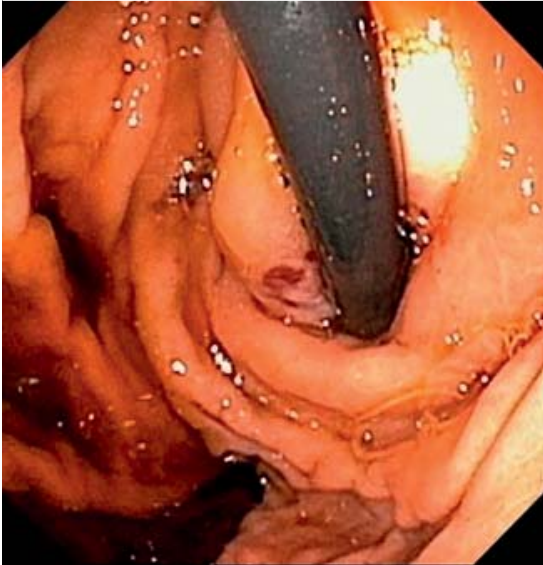

Fig. 2 An ultraslim scope was used to confirm adequacy and position of tunneling (two scope method).

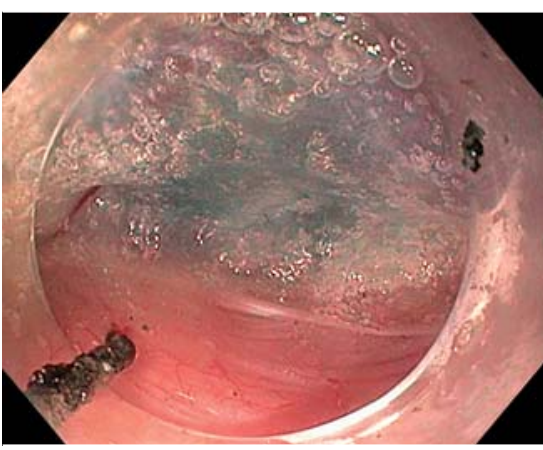

- Fig. 3 Pre-tunnel submucosal injection navigated the direction of tunnel and reduced the number of injections needed inside the tunnel.

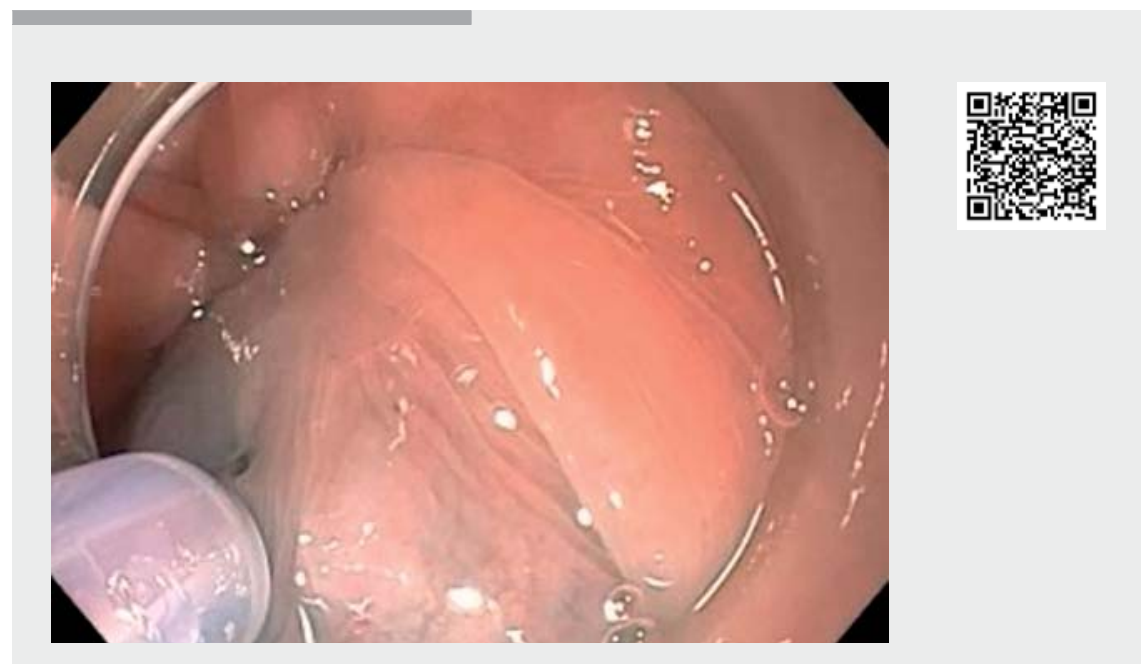

Video 1 Minimizing reflux after peroral endoscopic myotomy using the navigational pocket technique.

Peroral endoscopic myotomy (POEM) is an established and effective treatment for patients with achalasia. However, post-POEM reflux is a common complication [1]. POEM with posterior approach enables better scope positioning and has similar efficacy to the anterior approach [2]. The gastric oblique muscles are contiguous with the circular muscles of the distal esophagus and important for preventing gastroesophageal reflux [3]. These muscle fibers are routinely encountered and easily disrupted on the posterior approach, which may increase the frequency of post-POEM reflux [4]. The oblique muscle fibers are most sparse along the lesser curvature [3]. A POEM strategy that minimizes disruption of the oblique muscles while maintaining the posterior approach may attenuate post-POEM reflux.

We present a modified posterior approach using a tunnel method, which allows predictable navigation of the myotomy to finish at the lesser curve of the stomach ( $\vee$ Video 1$)$. The patient was a 73-year-old woman with type II achalasia. Submucosal injection of saline with methylene blue was performed at entry point. Subsequently, injections were performed in a spiral fashion toward the lesser curvature of the stomach, resulting in continuous mucosal elevation with the desired submucosal tunnel configuration ( $\triangleright$ Fig. 1). The standard POEM procedure was then performed. After tunneling, an ultraslim scope was used to confirm that the end of the tunnel was in the lesser curvature ( $\triangleright$ Fig. 2 ).

By modifying the standard posterior approach for POEM, we devised a method to minimize disruption of the oblique muscles and potentially decrease postPOEM reflux. Creating a submucosal pocket by serial injections through the mucosa with visual guidance to the lesser curve of the stomach overcomes the limitation of navigating from within the tunnel. In addition, fewer injections are required inside the tunnel ( $\triangleright$ Fig.3). By merely following the pre-injected blue color, the navigation within the tunnel was clear and predictable.

Endoscopy_UCTN_Code_TTT_1AO_2AJ 


\section{Competing interests}

The authors declare that they have no conflict of interest.

The authors

\section{Rintaro Hashimoto, Kenneth J. Chang}

H. H. Chao Comprehensive Digestive Disease Center, Division of Gastroenterology and Hepatology, Department of Medicine, University of California, Irvine, Orange, California, United States

\section{Corresponding author}

\section{Rintaro Hashimoto, MD}

Division of Gastroenterology, University of California Irvine, 333 City Blvd West, Suite 400, Orange, CA, 92868, United States

Fax: +1-714-456-7753

rinhashimoto@gmail.com

\section{References}

[1] Kumbhari V, Familiari P, Bjerregaard NC et al. Gastroesophageal reflux after peroral endoscopic myotomy: a multicenter case-contro study. Endoscopy 2017; 49: 634-642

[2] Khashab MA, Sanaei O, Rivory J et al. Peroral endoscopic myotomy: anterior versus posterior approach: a randomized single-blinded clinical trial. Gastrointest Endosc 2019. doi:10.1016/j.gie.2019.07.034

[3] Zifan A, Kumar D, Cheng LK et al. Threedimensional myoarchitecture of the lower esophageal sphincter and esophageal hiatus using optical sectioning microscopy Sci Rep 2017; 7: 13188

[4] Grimes KL, Bechara R, Shimamura Y et al. Gastric myotomy length affects severity but not rate of post-procedure reflux: 3-year follow-up of a prospective randomized controlled trial of double-scope per-oral endoscopic myotomy (POEM) for esophageal achalasia. Surg Endosc 2019. doi:10.1007| s00464-019-07079-0

\section{Bibliography}

DOI https://doi.org/10.1055/a-1097-4867

Published online: 5.2.2020

Endoscopy 2020; 52: E277-E278

(c) Georg Thieme Verlag KG

Stuttgart · New York

ISSN 0013-726X

\section{ENDOSCOPY E-VIDEOS \\ https://eref.thieme.de/e-videos}

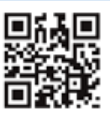

Endoscopy E-Videos is a free access online section, reporting on interesting cases and new

techniques in gastroenterological endoscopy. All papers include a high quality video and all contributions are freely accessible online.

This section has its own submission website at https://mc.manuscriptcentral.com/e-videos 